\title{
Meningkatkan Kesehatan Lansia Dengan Terapi Infrared Dan Pengecekan Tensi Ranting Aisiyah Prenggan
}

\author{
Erika Loniza1, Meilia Safitri² \\ Teknik Elektromedik, Vokasi, Universitas Muhammadiyah Yogyakrta, Jl. Brawijaya Kasihan, Bantul Yogyakarta 5518, Tlp (0274) 387656 \\ Email: erika@umy.ac.id \\ DOI: $10.18196 / p p m .32 .208$
}

\begin{abstract}
Abstrak
Aisyiyah salah satu organisasi otonom di Muhammadiyah. Aisyiyah merupakan gerakan wanita Islam yang mendobrak kebekuan feodalisme dan ketidaksetaraan gender secara hierarki keorganisasian. Ranting Aisyiyah Prenggan beranggotakan dari usia dewasa hingga lanjut usia. Seiring bertambahnya usia, tubuh mengalami penurunan fungsi pada berbagai sistem, baik masalah pada sistem muskuloskeletal maupun sistem kardiovaskuler. Permasalahan yang dihadapi mitra dalam hal ini Ranting Aisyiyah PRA Prenggan adalah kurangnya pemahaman kesehatan terkait masalah nyeri atau kekakuan otot dan hipertensi sehingga penulis melakukan pengabdian masyarakat yang meliputi pelatihan, penyuluhan, dan pendampingan. Tujuan dari pengabdian masyarkat ini adalah meningkatkan penatalaksanaan farmakologi dan nonfarmakologi ibu-ibu Aisyiyah Prenggan. Metode yang dilakukan antara lain penyuluhan tentang pemahaman nyeri, kekakuan otot dan terapi nyeri secara gratis, pelatihan cara mengoperasikan alat terapi infrared, dan penghibahan peralatan kesehatan untuk Kader PRA Prenggan. Program ini meningkatkan pemahaman partisipan tentang nyeri dan terapi nyeri, meningkatkan partisipan dapat mengoperasikan alat terapi infrared, dan meningkatkan kemampuan cek tekanan darah dengan mengunakan tensi digital dan alat terapi infrared.
\end{abstract}

Kata Kunci: Lansia, Kesehatan, Terapi Infrared

\section{Pendahuluan}

Aisyiyah merupakan salah satu organisasi otonom yang ada di Muhammadiyah. Kiai Haji Ahmad Dahlan sebagai pendiri Muhammadiyah sangat memerhatikan pembinaan terhadap wanita ("Profil Muhammadiyah Bantul.Pdf," n.d.). Aisyiyah menjadi gerakan wanita Islam yang mendobrak kebekuan feodalisme dan ketidaksetaraan gender secara hierarki keorganisasian. Aisyiyah ranting merupakan level organisasi paling bawah yang setara level kelurahan. Aisyiyah dalam satu abad ini di Indonesia memiliki 33 pimpinan wilayah, setara provinsi, 370 pimpinan daerah setingkat kabupaten, 2332 pimpinan cabang setingkat kecamatan, dan 6924 pimpinan ranting setingkat kelurahan. Ranting Aisyiyah Prenggan merupakan salah satu ranting setingkat kelurahan di Kotagede. Ranting Aisyiyah Prenggan memiliki anggota dan simpatisan sebanyak 80 orang yang tersebar di Kelurahan Prenggan dan Kelurahan Purbayan. Ranting ini berjarak $12 \mathrm{~km}$ dari Kampus Universitas Muhammadiyah Yogyakarta. Aisyiyah mempunyai beberapa tujuan. Salah satu tujuan Aisyiyah adalah menggerakan dan menghidupsuburkan amal tolong-menolong dalam kebijakan dan ketaqwaan (Rahmawati, Safitri, and Manajemen 2020). Untuk mencapai tujuan tersebut, kami sebagai pengajar dan peneliti di bidang Teknologi Elektro-Medis bertujuan mentransfer ilmu pengetahuan dan teknologi ke Ranting Aisiyah Prenggan Kotagede dengan melakukan pelatihan, penyuluhan, dan pendampingan alat kesehatan berupa lampu terapi infra red dan tensi meter digital.

Ranting Aisyiyah Prenggan memiliki anggota mulai usia dewasa hingga lanjut usia. Lanjut usia (lansia) merupakan fase akhir kehidupan yang ditandai dengan penuaan yang menjadi proses normal kehidupan. Lansia mempunyai Usia Harapan Hidup (UHH) cukup tinggi. Di Indonesia, salah satu kota yang memiliki UHH dengan populasi lansia tertinggi adalah Dearah Istimewah Yogyakarta dengan persentase jumlah lansia sebesar 13,05\% (Uda, Muflih, and Amigo 2017). Secara normal, seiring bertambahnya usia tubuh mengalami penurunan fungsi pada berbagai sistem, salah satunya adalah sistem 
musculoskeletal. Penurunan fungsi sistem musculoskeletal menyebabkan lansia rentan mengalami hambatan mobilitas fisik. Masalah hambatan mobilitas fisik pada lansia yang dapat terjadi berupa penurunan kekuatan otot serta kekakuan dan nyeri pada sendi (Ismaningsih, Zein, and Sari 2019). Oleh karena itu, diperlukan penatalaksanaan farmakologi dan nonfarmakologi untuk mengurangi nyeri, mempertahankan dan meningkatkan kekuatan otot (Uda, Muflih, and Amigo 2017)(Ridha and Putri 2015). Selain masalah pada sistem musculoskeletal, lansia juga rentan mengalami masalah pada sistem kardiovaskuler.seperti hipertensi.

Hipertensi merupakan salah satu Penyakit Tidak Menular (PTM) yang ditandai dengan meningkatnya tekanan darah sistolik lebih dari sama dengan $140 \mathrm{mmHg}$ dan diastolik lebih dari sama dengan $90 \mathrm{mmHg}$ (Yonata and Satria 2016). Hasil penelitian Iswahyuni (2017) menunjukkan bahwa dari 90 lansia mengalami hipertensi sistole (tekanan darah systole lebih $140 \mathrm{mmHg}$ ) yang termasuk kategori hipertensi ringan ada 42 lansia (46,7\%), hipertensi sedang 37 lansia $(41,1 \%)$, dan yang mengalami hipertensi berat 11 lansia (12,2\%). Dilihat dari tekanan darah diastolenya, dari 90 lansia yang termasuk kategori hipertensi ringan, ada 41 lansia $(45,6 \%)$ dan hipertensi sedang 48 lansia (53,3\%). Pada penderita hipertensi, cek tekanan darah secara rutin perlu dilakukan agar dapat memanajemen kesehatan sehingga tubuh berfungsi dengan baik (Iswahyuni 2017).

Adapun permasalahan yang dihadapi mitra, Ranting Aisyiyah PRA Prenggan, adalah kurangnya pemahaman kesehatan ibu-ibu PRA Prenggan terhadap ganguan gerak fungsional, seperti rasa nyeri, otot-ototnya kaku yang mengakibatkan aktivitas fungsional dalam kehidupan sehari-hari tergangu. Hal ini dialami seluruh para wanita yang sudah menikah. Rinciannya adalah $25 \%$ lansia mengalami osteoporosis, $45 \%$ ibu produktif mengalami nyeri dibagian pungung dan pinggang mereka, $10 \%$ mengalami tekanan darah tinggi, $15 \%$ tekanan darah stabil dan rasa nyeri ringan, dan 5\% tekanan darah rendah.

Berdasarkan permasalah yang ada, penulis melakukan pengabdian masyarakat, meliputi pelatihan, penyuluhan, dan pendampingan. Penyuluhan yang dilakukan ialah penyuluhan tentang pemahaman nyeri, kekakuan otot, dan terapi nyeri secara gratis. Pelatihan yang dilakukan adalah pelatihan cara mengoperasikan alat terapi infrared dan peralatan kesehatan yang akan dihibahkan untuk kader PRA Prenggan. Tujuannya adalah mengobati kader yang sakit dengan terapi infrared dan dapat sedikit meringkan biaya pengobatan kader.

\section{Metode Pelaksanaan}

Permasalahan di ranting Aisiyah Prenggan Kotagede, Yogyakarta yang berkaitan dengan kesehatan para lansia adalah belum adanya pelatihan dan pendampingan penggunaan alat kesehatan di lingkungan Ranting Aisiyah Prenggan Kotagede dan belum adanya kesadaran dalam pemahaman kesehatan ibu-ibu PRA Prenggan terhadap ganguan gerak fungsional, seperti rasa nyeri, otot-ototnya kaku yang dapat mengakibatkan aktivitas fungsional dalam kehidupan sehari-hari. Lokasi pelaksanaan pengabdian masyarakat ini di Balai RW 10 Turnojayan. Dalam pelaksanaan pengabdian masyarakat ini, beberapa tahapan dilakukan. Secara detail metode dan mekanisme pelaksanaan kegiatan pengabdian ini dapat diuraikan sebagai berikut.

1. Analisis lapangan, yaitu mengidentifikasi permasalahan yang terjadi pada Posyandu Lansia Ranting Aisyiyah Prenggan Kotagede

2. Melakukan kerja sama dengan mitra, dilakukan diawal sebelum pengabdian ini dilaksanakan di Posyandu Ranting PRA Prenggan berupa penandatangan surat kesedian menjadi mitra pelaksanaan pengabdian masyarakat

3. Metode penyuluhan penggunaaan peralatan terapi, sehingga kader dapat mengoperasi peralatan terpai secara baik dan sesuai aturan pakai 
4. Metode pelatihan, dilakukan dengan menggunakan teknologi infrared, memberikan pelatihan keknik dasar penggunaan alat infrared kepada kader, dan penanganan langsung fisioterapi pada lansia secara gratis sehingga ketika kader memberikan penangan kepada lansia tidak mengalami kesulitan

5. Metode pendampingan, dilakukan dengan cara memberikan pendampingan selama tiga bulan berturut-turut sehingga apa yang telah diberikan dan disampaikan oleh fisioterapi dapat berjalan dengan baik.

\section{Memberikan Penyuluhan}

Kegiatan penyuluhan dilakukan di Balai RW 10 Trunojayan dihadiri oleh lansia dan para pengurus ranting. Dalam penyuluhan ini, tim memberikan ceramah upaya agar kesehatan lansia tetap terjaga sampai akhir hayat. Mengedukasi para lansia untuk tetap semangat karena terkadang lansia merasa dirinya tidak berguna di hadapan keluarga dan masyarakat. Mereka merasa menjadi beban. Hal ini membuat kesehatan lansia menurun. Penyuluhan juga memberikan penjelasan Teknik dan manfaat infrared bagi Lansia dan Keluarga. Penyuluhan dan pelatihan dilakukan mulai pukul 13.30 sampai dengan 17.00. Penyuluhan ditunjukan pada Gambar 3. Penyuluhan dilakukan terlebih dahulu agar kegiatan pada hari kedua para lansia dan keluarga telah memahami manfaat dan cara penggunaan lampu infrared. Pada saat penyuluhan ini juga diberikan bantuan alat infrared, tensimeter, serta perlengkapan ketika terapi dan pengecekan kepada kader Aisiyah Prenggan. Tujuan pemberian ini adalah agar pada saat kegiatan majekis kesehatan pada setiap bulannya, infrared dan tensimeter dapat dipergunakan secara baik. Dalam penyuluhan dilakukan sesi tanya jawab kepada para seluruh ibu kader Aisiyah Prenggan. Gambar 1 merupakan dokumentasi ketika sesi tanya jawab pada saat pelatihan dan penyuluhan alat kesahatan dan tata cara menggunkan alat terapi infrared.

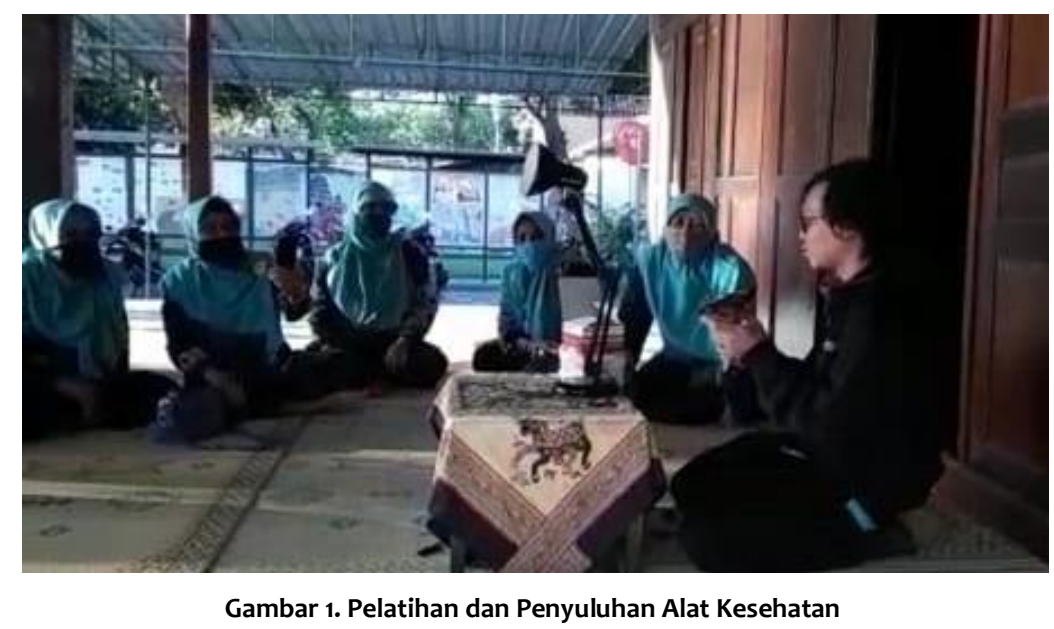

\section{Fisiotrapi InfraRed dan Pengecekan Tensi}

Pada pertemuan kedua pengabdian dilakukan dengan agenda penanganan angsung oleh tim pengabdian. Pemberian sinar infrared ini dilakukan selama 15 menit pertama, kemudian 15 menit berikutnya. Pemberian terpai sinar infrared ini membuat sirkulasi darah dalam tubuh lansia akan lancer. Akibatnya, ganguan-ganguan kesehatan yang dihadapi lansia menjadi berkurang. Gambar 2 merupakan dokumentasi pada saat warga melakukan terapi infrared dan pada gambar 3 merupakan dokumentasi ketika warga melakukan pengecekan tensi dengan tensi meter digital. 


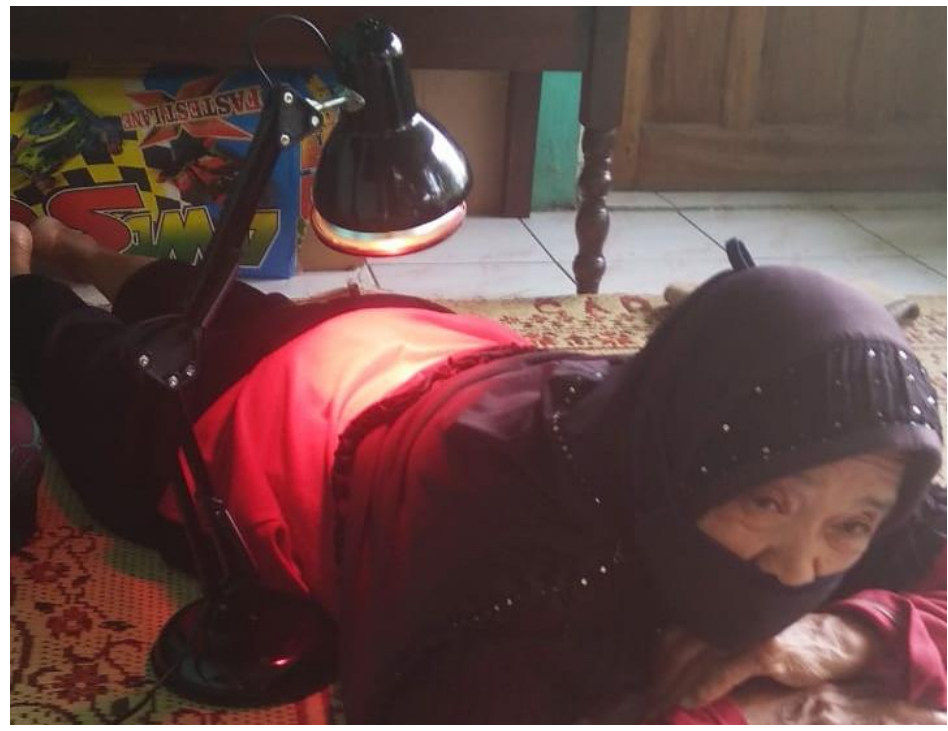

Gambar 2. Pasien pada saat Terapi Infrared

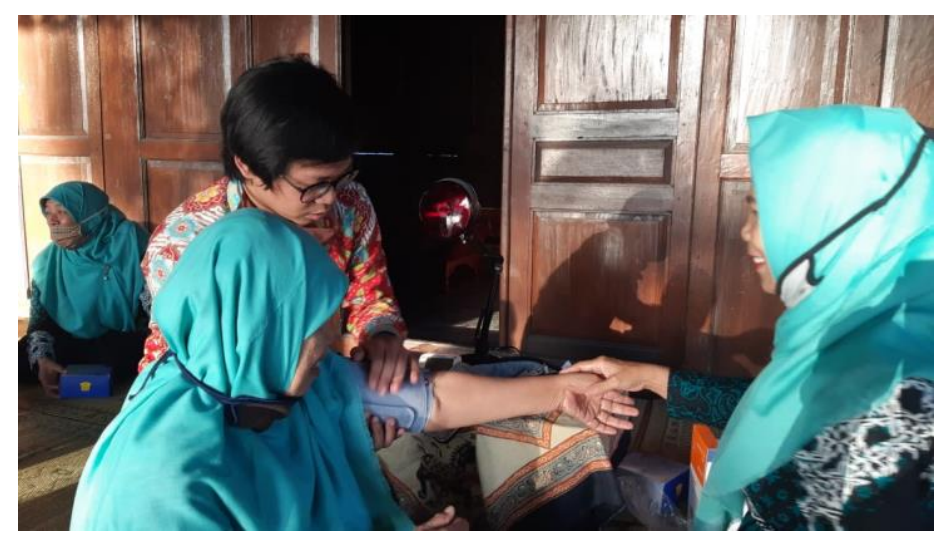

\section{Hasil dan Pembahasan}

Gambar 3. Pengecekan Tensi Lansia

Target dari kegiatan ini adalah untuk mempererat tali silaturahmi antaranggota kader dan pengurus kader PRA Prenggan, meningkatkan rasa tolong-menolong antarsesama umat, serta dari segi kesehatan dilakukan untuk meningkatkan aktivitas gerak dan kualitas hidup. Oleh karena itu, dengan adanya terapi nyeri tersebut diharapakan kader PRA akan lebih aktif dalam menjalankan tugas-tugasnya dan dapat mentransfer ilmu kepada keluarga dan warga setempat. Tabel 1 merupakan data peserta kegiatan Ppngabdian masyarakat.

Tabel 1. Peserta Kegitan Pengabdian Masyarakat

\begin{tabular}{lcc}
\hline Karaktersitik & Frekuensi (F) & persentase (\%) \\
\hline Umur & & \\
$55-59$ tahun & 1 & 3,22 \\
$60-74$ tahun & 22 & 70,98 \\
$>75$ tahun & 8 & 25,8 \\
& jenis Kelamin & \\
perempuan & 24 & 77,4 \\
laki-laki & 7 & 22,6 \\
\hline
\end{tabular}

Hasil Pengecekan tensi kesehatan lansia Ranting Aisyiyah Prenggan RW 10 ditunjukkan pada tabel 2. 
Tabel 2. Data Warga yang melakukan pengecekan Tensi di kegitan Pengabdian Masyarakat

\begin{tabular}{|c|c|c|c|c|}
\hline Nama & Usia & TB & BB & TD \\
\hline Ny.SR & 70 thn & $141 \mathrm{~cm}$ & $41 \mathrm{~kg}$ & $132 / 70 \mathrm{mmHg}$ \\
\hline Ny.SH & 66 thn & $141 \mathrm{~cm}$ & $44 \mathrm{~kg}$ & $125 / 75 \mathrm{mmHg}$ \\
\hline Tn.RB & 69 thn & $167 \mathrm{~cm}$ & $60 \mathrm{~kg}$ & $150 / 90 \mathrm{mmHg}$ \\
\hline Ny.SW & 72 thn & $148 \mathrm{~cm}$ & $38 \mathrm{~kg}$ & $130 / 70 \mathrm{mmHg}$ \\
\hline Ny.HS & 79 thn & $148 \mathrm{~cm}$ & $50 \mathrm{~kg}$ & $150 / 80 \mathrm{mmHg}$ \\
\hline Ny.S & 69 thn & $147 \mathrm{~cm}$ & $49 \mathrm{~kg}$ & $135 / 75 \mathrm{mmHg}$ \\
\hline Ny.DA & 60 thn & $143 \mathrm{~cm}$ & $53 \mathrm{~kg}$ & $130 / 80 \mathrm{mmHg}$ \\
\hline Ny.ON & 64 thn & $152 \mathrm{~cm}$ & $68 \mathrm{~kg}$ & $138 / 80 \mathrm{mmHg}$ \\
\hline Tn.HKA & 76 thn & $151 \mathrm{~cm}$ & $49 \mathrm{~kg}$ & $140 / 80 \mathrm{mmHg}$ \\
\hline Ny.HTNA & 74 thn & $147 \mathrm{~cm}$ & $45 \mathrm{~kg}$ & $130 / 70 \mathrm{mmHg}$ \\
\hline Ny.SM & 57 thn & $143 \mathrm{~cm}$ & $65 \mathrm{~kg}$ & $150 / 80 \mathrm{mmHg}$ \\
\hline Tn.S & 80 thn & $150 \mathrm{~cm}$ & $58 \mathrm{~kg}$ & $165 / 80 \mathrm{mmHg}$ \\
\hline Ny.HSH & 79 thn & $145 \mathrm{~cm}$ & $46 \mathrm{~kg}$ & $110 / 60 \mathrm{mmHg}$ \\
\hline Tn.M & 60 thn & $159 \mathrm{~cm}$ & $73 \mathrm{~kg}$ & $120 / 70 \mathrm{mmHg}$ \\
\hline Tn.H & 76 thn & $153 \mathrm{~cm}$ & $48 \mathrm{~kg}$ & $140 / 80 \mathrm{mmHg}$ \\
\hline Tn.HSH & 88 thn & $162 \mathrm{~cm}$ & $48 \mathrm{~kg}$ & $180 / 90 \mathrm{mmHg}$ \\
\hline Ny.SK & 66 thn & $142 \mathrm{~cm}$ & $52 \mathrm{~kg}$ & $150 / 80 \mathrm{mmHg}$ \\
\hline Tn.MS & 87 thn & $152 \mathrm{~cm}$ & $68 \mathrm{~kg}$ & $180 / 90 \mathrm{mmHg}$ \\
\hline Ny.SA & 67 thn & $141 \mathrm{~cm}$ & $52 \mathrm{~kg}$ & $140 / 85 \mathrm{mmHg}$ \\
\hline Ny.D & 68 thn & $145 \mathrm{~cm}$ & $60 \mathrm{~kg}$ & $130 / 80 \mathrm{mmHg}$ \\
\hline Ny.ES & 57 thn & $143 \mathrm{~cm}$ & $55 \mathrm{~kg}$ & $120 / 70 \mathrm{mmHg}$ \\
\hline Ny.A & 64 thn & $153 \mathrm{~cm}$ & $59 \mathrm{~kg}$ & $110 / 60 \mathrm{mmHg}$ \\
\hline Tn.P & 68 thn & $155 \mathrm{~cm}$ & $42 \mathrm{~kg}$ & $110 / 70 \mathrm{mmHg}$ \\
\hline Ny.TP & $61 \mathrm{thn}$ & $141 \mathrm{~cm}$ & $44 \mathrm{~kg}$ & $120 / 60 \mathrm{mmHg}$ \\
\hline Ny.K & 62 thn & $145 \mathrm{~cm}$ & $65 \mathrm{~kg}$ & $120 / 70 \mathrm{mmHg}$ \\
\hline Tn.UH & 77 thn & $159 \mathrm{~cm}$ & $48 \mathrm{~kg}$ & $130 / 80 \mathrm{mmHg}$ \\
\hline Ny.F & $61 \mathrm{thn}$ & $148 \mathrm{~cm}$ & $72 \mathrm{~kg}$ & $150 / 90 \mathrm{mmHg}$ \\
\hline Ny.SS & 73 thn & $148 \mathrm{~cm}$ & $43 \mathrm{~kg}$ & $190 / 70 \mathrm{mmHg}$ \\
\hline Ny.HR & 73 thn & $150 \mathrm{~cm}$ & $45 \mathrm{~kg}$ & $100 / 60 \mathrm{mmHg}$ \\
\hline Ny.S & 70 thn & $142 \mathrm{~cm}$ & $44 \mathrm{~kg}$ & $135 / 100 \mathrm{mmHg}$ \\
\hline Tn.EP & 64 thn & $158 \mathrm{~cm}$ & $60 \mathrm{~kg}$ & $150 / 80 \mathrm{mmHg}$ \\
\hline
\end{tabular}

Dari hasil pelaksanaan pengabdian, rata-rata masyarakat dan Ranting Aisiyah merespons dengan baik kegiatan yang dilakukan. Warga dan Ranting Aisiyah Prenggan berharap agar kegiatan pengabdian masyarakat ini di tahun depan dilakukan lagi di Ranting Aisiyah Prenggan. Hasil respons peserta di tunjukan pada Tabel 3.

\begin{tabular}{lcc}
\multicolumn{3}{c}{ Tabel 3. Evaluasi Kegiatan Pengabdian Masyarakat } \\
\hline $\begin{array}{l}\text { Katagori } \\
\text { (respon Warga ) }\end{array}$ & $\begin{array}{c}\text { Frekuensi } \\
(\mathrm{F})\end{array}$ & $\begin{array}{c}\text { Persentase } \\
(\%)\end{array}$ \\
\hline Baik & 31 & 100 \\
Tidak Baik & 0 & 0 \\
jumlah & 31 & 100 \\
& & \\
\hline
\end{tabular}

Selain itu, dalam pengabdian ini, tim dalam melaksanakan tugas menghasilkan dan menemukan beberapa hal sebagai berikut .

1. Peningkatan derajat kesehatan lansia di Ranting Aisiyah Kotagede setelah dilakukan penyuluhan dan pemberian sinare Infrared

2. Lansia dan keluarga dan anggota majelis menjadi paham akan manfaat sinar infrared dan teknik penggunaan alat infrared tersebut .

Selain penggunaan alat tensimeter dalam pengukuran tekanan darah, pelatihan dan pendampingan terkait pengoperasian alat terapi infrared juga dilakukan. Pada saat fisioterapi, 
dilakukan pemeriksaan dan terapi infrared. Berdasarakan penelitian, cedera dapat diobati dengan cara fisioterapi infrared (Widowati, Murti, and Pamungkasari 2017) sehingga kegiatan ini memberikan edukasi kesehatan terkait terapi yang dapat dilakukan dengan menggunakan infrared dan kegiatan yang harus dilakukan pada kader-kader lanjut usia atau kader yang mengalami cedera. Bagi kader yang saat ini dalam keadan sehat, dianjurkan untuk selalu melakukan gerakan-gerakan peregangan agar otot-otot tidak kaku dan tetap menjaga pola hidup yang sehat (Santoso and Prasetyo 2018). Dalam kegiatan ini, penyuluhan gerakangerakan sehat dan pelatihan penggunaan bantal terapi juga dilakukan. Dengan kegiatan ini, nantinya kader diharapkan dapat secara berkala melakukan terapi pada bagian yang nyeri sehingga mampu melakukan aktivitas sehari-hari dengan sehat dan bermanfaat.

\section{Kesimpulan}

Berdasarkan dari hasil pengabdian masyarakat ini, dapat disimpulkan bahwa pemahaman partisipan tentang nyeri dan terapi nyeri meningkat.P partisipan dapat mengoperasikan alat terapi infrared. Cek tekanan darah juga telah dilakukan di PRA Prenggan. Target pengabdian tercapai sesuai harapan yang telah di tetapkan di awal.

\section{Ucapan Terima Kasih}

Kami mengucapkan terima kasih kepada Lembaga.Penelitian Publikasi dan Pengabdian Masyarakat (LP3M) Universitas Muhammadiyah Yogyakarta, Pimpinan Ranting Aisisyah Prenggan Kotagede, Yogyakarta yang telah berpartisipasi pada pelaksanaan Program Pengabdian di Balai RW Turnojoyo Kotagede Yogyakarta . Kami berharap program-program pengabdian ini dapat dilanjutkan dan dapat bermanfaat bagi masyarakat luas.

\section{Daftar Pustaka}

Ismaningsih, Renny Hidayati Zein, and Dian Citra Sari. 2019. "Pengaruh Lama Duduk Terhadap Kasus Low Back Pain Myogenik Dengan Modalitas Infrared Dan William Flexion Excercise Pada Siswa Madrasah Aliya Di Pekanbaru." Jurnal Ilmiah Fisioterapi (JIF) 2 (2): 39-44. http://jurnal.univrab.ac.id/index.php/jif/article/view/1002/623.

Iswahyuni, Sri. 2017. "Hubungan Antara Aktifitas Fisik Dan Hipertensi Pada Lansia.” Profesi (Profesional Islam) : Media Publikasi Penelitian 14 (2): 1.

https://doi.org/10.26576/profesi.155.

"Profil Muhammadiyah Bantul.Pdf." n.d.

Rahmawati, Fitri Maulidah, Teti Anggita Safitri, and Program Studi Manajemen. 2020.

"Pelatihan Kewirausahaan Di Lingkungan Ranting “Aisyiyah Tinalan Kotagede," 218-20.

Ridha, M. Rasyid, and Miko Eka Putri. 2015. "Kekuatan Otot Ekstremitas Bawah Pada Lansia Dengan OSTEOARTHRITIS DI WILAYAH KERJA PUSKESMAS KONI KOTA JAMBI." Jurnal Akademika Baiturrahim 4 (2): 45-52.

Santoso, Ari, and Eko Budi Prasetyo. 2018. "Penatalaksanaan Fisioterapi Pada Kondisi Trigger Finger Dengan Intervensi Ultrasound (Us), Infrared (Ir) Dan Transverse Friction Di Rsud Bendan Pekalongan.” Jurnal Fisioterapi Dan Rehabilitasi 2 (2): 44-52.

https://doi.org/10.33660/jfrwhs.v2i2.22. 
Uda, Hermina Desiane Hastini, Muflih Muflih, and Thomas Aquino Erjinyuare Amigo. 2017. "Latihan Range of Motion Berpengaruh Terhadap Mobilitas Fisik Pada Lansia Di Balai Pelayanan Sosial Tresna Werdha Unit Abiyoso Yogyakarta." Jurnal Ners Dan Kebidanan Indonesia 4 (3): 169. https://doi.org/10.21927/jnki.2016.4(3).169-177.

Widowati, Risna, Bhisma Murti, and Eti Poncorini Pamungkasari. 2017. "Effectiveness of Acupuncture and Infrared Therapies for Reducing Musculoskeletal Pain in the Elderly." Indonesian Journal of Medicine 02 (01): 41-51. https://doi.org/10.26911/theijmed.2017.02.01.05.

Yonata, Ade, and Arif Putra Pratama Satria. 2016. "Hipertensi Sebagai Faktor Pencetus Terjadinya Stroke.” Majority 5 (2): 17. 